\title{
Portugal's special education law: implementing the International Classification of Functioning, Disability and Health in policy and practice
}

\author{
Manuela Sanches-Ferreira ${ }^{1}$ Rune J. Simeonsson ${ }^{2}$, Monica Silveira-Maia $^{1}$ Silvia Alves ${ }^{1}$ \\ Ana Tavares ${ }^{1} \&$ Sara Pinheiro ${ }^{1}$ \\ ${ }^{7}$ Special Education Department, School of Education, Porto Polytechnic, Rua Dr. Roberto Frias, 602, Porto, 4200-465 Portugal \\ and ${ }^{2}$ University of North Carolina, Chapel Hill, NC, USA
}

Purpose: The International Classification of Functioning, Disability and Health (ICF) was introduced in Portuguese education law as the compulsory system to guide eligibility policy and practice in special education. This paper describes the implementation of the ICF and its utility in the assessment process and eligibility determination of students for special education. Methods: A study to evaluate the utility of the ICF was commissioned by the Portuguese Ministry of Education and carried out by an external evaluation team. A document analysis was made of the assessment and eligibility processes of 237 students, selected from a nationally representative sample. Results: The results provided support for the use of the ICF in student assessment and in the multidimensional approach of generating student functioning profiles as the basis for determining eligibility. The use of the ICF contributed to the differentiation of eligible and non eligible students based on their functioning profiles. Conclusions: The findings demonstrate the applicability of the ICF framework and classification system for determining eligibility for special education services on the basis of student functioning rather than medical or psychological diagnose.

Keywords: Children with disabilities, functioning, ICF, legislation, profile, special education

\section{Introduction}

Although the proportion of students who receive special education services varies across Western countries, eligibility for such services has usually taken the form of a child meeting criteria for a diagnosis or category of disability [1]. In contrast to the standard medical diagnosis and classification

\section{Implications for Rehabilitation}

The use of the International Classification of Functioning, Disability and Health (ICF) framework in special education policy is as follows:

- The functional perspective of the ICF offers a more comprehensive, holistic assessment of student needs than medical diagnoses.

- CF-based assessment of the nature and severity of functioning can serve as the basis for determining eligibility for special education and habilitation.

- Profiles of functioning can support decision making in designing appropriate educational interventions for students.

provided by ICD-10 [2], the field of education has lacked a coherent and universal approach for assigning diagnoses and categories to children with disabilities. This has resulted not only in inconsistencies in determining eligibility of children with disabilities but also in comparing prevalence within and across countries [3]. Perhaps the most significant limitation has been the lack of correspondence between diagnoses and the learning and social problems faced by students. In this context, the determination of eligibility should be based on the documentation of the functional difficulties students have in meeting the academic and adaptive demands of the school environment [4].

The publication of the International Classification of Functioning, Disability and Health (ICF) [5] and the derived version for Children and Youth [6] offers a common language for determining special education eligibility

Correspondence: Manuela Sanches-Ferreira, Special Education Department, School of Education, Porto Polytechnic, Rua Dr. Roberto Frias, 602, Porto, 4200-465 Portugal. E-mail: manuelaferreira @ese.ipp.pt 
based on limitations of functioning. Specifically, the ICF is based on a conceptual model consistent with a holistic and interdisciplinary approach to describe childhood disability [7]. It also provides a comprehensive taxonomy to separately document the dimensions of impairments of Body Functions and structures, limitations of activities, restrictions of participation and the role of Environmental Factors [8]. Within this perspective, eligibility for special education should focus on characteristics that define the nature and extent of a student's performance limitations in meeting the physical, social and psychological demands relevant to learning in the school environment.

The functional basis for disability defined in the ICF is consistent with the mandate for inclusive education in special education policies and legislation of the last two decades. Further, the biopsychosocial paradigm of disability in the ICF paralleled advances in improvements in human rights and in scientific knowledge. International statements and documents such as the Salamanca Statement (1994) and U.N. Conventions on the Rights of the Child (1989) and the Rights of People with Disabilities (2006) recognize that schools must respond to the diverse needs of students with disabilities and that they should have access to education on an equal basis with all students.

In response to these parallel initiatives Portugal introduced a new special education law - Decree-Law n.03/2008 [9]. The preamble of the law explicitly states "A educa<;:ao inclusiva visa a equidade educativa (...) quer no acesso quer nos resultados (...) dando lugar a mobiliza<;:ao de servi<;:os especializados para promover o potencial de funcionamento biopsicosocial:' (Inclusive education aims for educational equity (...) whether in access or in outcomes $(. .$.$) conducive to the mobilization of specialized$ services to promote the biopsychosocial functioning potential). The target group for special education services was defined as students with "significant limitations in terms of activity and participation in one or more areas in life due to permanent functional and structural issues, which result in continued difficulty in terms of communication, learning, mobility, autonomy, interpersonal relationships and social involvement [10]".
The above definition encompasses a replacement of a medical or psychological diagnosis with a profile of the student's functioning as the basis for determining eligibility for special education. In this regard, the interdisciplinary team uses the ICF as a comprehensive framework to assess the student's capacities and performance. The assessment results are described within the ICF taxonomy [5] related to three main components of functioning and disability: Activities and Participation, Environmental Factors and Body Functions.

A year following the passage of the Decree-Law n. ${ }^{03 / 2008,}$ the Portuguese Ministry of Education requested a study to evaluate the utility of the ICF in the implementation of the law [11]. A major focus of the study was to examine the role of the ICF in reference to Articles 5 and 6 relating to the referral and assessment process, respectively. Of related interest was the analysis of contribution of the ICF in determining eligibility for students with disabilities for special education services and defining elements of the Individualized Education Program (IEP). The plan was to examine these issues by reviewing four standard documents used to record the identification and assessment process of students referred for special education services. The documents and their content are described below and the sequence of their use in the decision making process under Portuguese special education law is illustrated in Figure 1.

The study approach was thus to review these primary documents in case studies of children who had been assessed for special education eligibility.

- Referral Form - This form describes concerns about students' difficulties which may require special support needs. Prior health reports or pedagogical documents, if available, are attached to this document. The referral may be initiated by parents or educational professionals.

- Plan for Specialized Assessment - Following a review and discussion of problems identified on the referral form, the determination is made if there should be further specialized assessment of the problems. In that event, the school principal may request the involvement of other disciplines or services (health services, specialized resource centers)

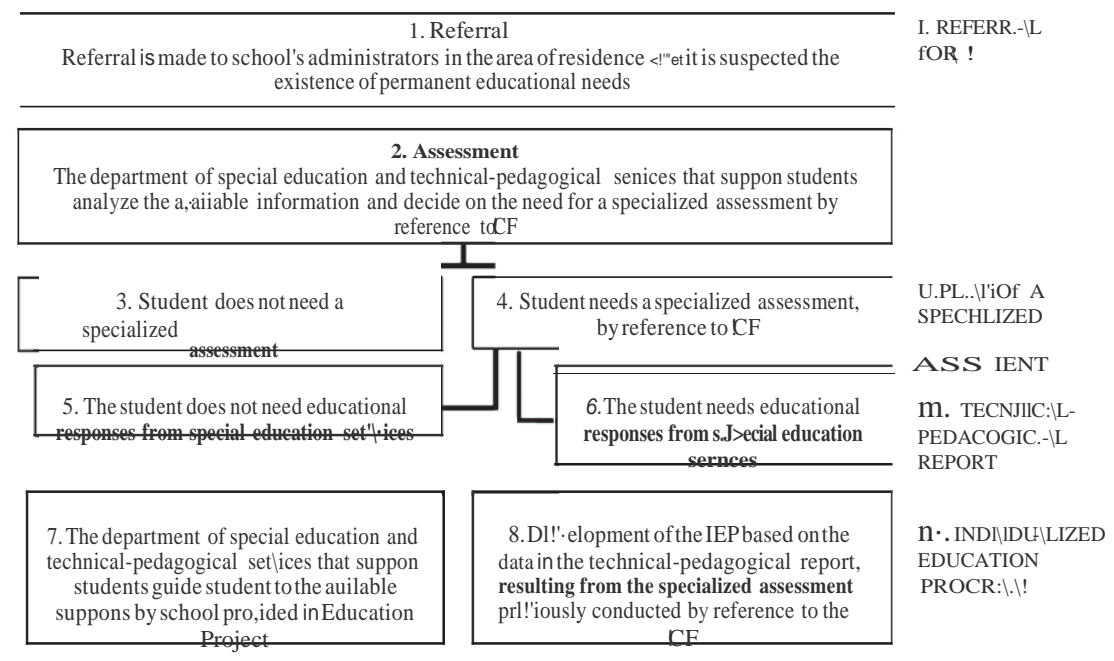

Figure 1. Portugal's special education process. Adapted from [12]. 
to form an interdisciplinary team together with parents and regular and special education teachers to assess the students' needs. The assessment process is then planned through identification of functioning categories of the child that are in need of assessment and defining who will gather the required information and how it will be done.

- Technical and Pedagogical Report (TPR): After the assessment results are analyzed, a TPR is prepared. This report includes; (a) the student's functioning profile based on data from the ICF components of Activities and Participation, Body Functions and Environmental Factors; (b) reasons supporting decision making regarding eligibility; and (c) selected educational measures. If the student's functioning profile fails to meet the eligibility criteria, the educational team recommends the student for other educational resources and services.

- IEP: If the student eligible for special education services, then an IEP was designed, specifying accommodations and modifications for the child's learning program. The design and implementation of the IEP requires an integrated and continuous process conducted by an interdisciplinary team (including regular and special education teachers, parents), and is coordinated by the regular teacher.

The aim of this study to evaluate the role of the ICF in Portugal's new special education law was approached in five research questions. (1) How was the ICF used in each phase of the special education process? (2) How are standard Directorate-General for Innovation and Curriculum Development (DGIDC) documents related to the ICF used in the referral and assessment process? (3) What information sources are used in the assessment process and are they related to the ICF? (4) What is the distribution ofICF components, chapters and codes in referral and assessment documents?

(5) What are the characteristics of student functioning and Environmental Factors defining eligibility decisions?

\section{Methods}

\section{Study design}

In order to answer the research questions we conducted a case studies approach, in which the students' processes were collected containing four standards documents: Referral Form, Plan for Specialized Assessment, TPR and IEP.

\section{Participants}

The collection of case studies was based on probability sampling of students from the five Regional Directorates of Education in Portugal. Given the different sizes of school clusters in the five directorates, proportional sampling was made of students from the total number of clusters within each directorate. Participants included students at all levels from elementary school through secondary. Sample sizes thus varied as a function of the makeup of the directorate ranging from the largest with 265 clusters to the smallest with 49 clusters. As a national study, case records represented students from schools selected randomly and stratified according to the: number of schools and number of students for each of the five regional educational boards; number of eligible students, and the school grades. In this context, we examined the assessment and eligibility processes of 237 students, with a mean age of 14 years, ranging from 8 to 22 years. The gender distribution was $67.5 \%$ boys and $32.5 \%$ girls.

\section{Procedures}

Following development of the sampling plan, school principals were contacted in order to obtain permission for collection and analysis of student records. Confidentiality of the collected information was assured by assigning a numeric code to the documents pertaining to each student (there was no personal information, or reference to school or regional education board). Information from 477 documents for 237 students was coded by three members of the research team using a review protocol created for the study. A deductive content analysis was made of meaningful concepts within the text in order to assign them to ICF categories applying Cieza's linking rules [13]. Interrater agreement of $94 \%$ concordance was achieved among the three observers. Subsequently, these data were introduced in the database compiled and processed using the SPSS.

\section{Results}

The presentation of the results is structured according to the five research questions.

\section{How was the ICF used in each phase of the special education process?}

The ICF use was declared compulsory only in the description of the student's functioning profile, in which the educational team gathers all the data from the student's assessment. However, its use began to spread to other phases. The primary context in which the ICF was used within the Decree-Law implementation was the referral, assessment and team process to determine the student's eligibility for special education services.

As indicated above, 477 documents were analyzed from the 237 case studies that constituted the sample for this study. Evidence of the ICF taxonomic structure was found in $49.9 \%(n=238)$ of the 477 examined documents - including documents of referral, decision making about the need of a specialized assessment, functioning profile and intervention goals. As shown in Table I, reference to the ICF classification was lowest for intervention goals, 5 of 160 IEPs (3.1\%) and highest for the generation of functioning profiles, 214 of 229 functioning profiles $(93.4 \%)$.

\section{How are standard DGIDC documents related to the ICF used in the referral and assessment process? \\ In conjunction with the passage of Decree-Law n. ${ }^{0} 3 / 2008$, the central service of the Ministry of Education (DGIDC) created a set of materials to guide and support its implementation [12]. Evidence for the use of these documents was found (Table II), with the DGIDC checklist and the IEP model representing the guidance materials most used.}


Table I. References to the International Classification of Functioning, Disability and Health within different phases of the special education process.

\begin{tabular}{|c|c|c|c|c|c|}
\hline & Referral & $\begin{array}{c}\text { Decision making about } \\
\text { the need of a specialized } \\
\text { assessment }\end{array}$ & $\begin{array}{c}\text { Functioning } \\
\text { profile }\end{array}$ & $\begin{array}{c}\text { Intervention } \\
\text { goals (IEP) }\end{array}$ & Total \\
\hline With ICFJi (\%) & $3(5.9 \%)$ & $16(43.2 \%)$ & $214(93.4 \%)$ & $5(3.1 \%)$ & $238(49.9 \%)$ \\
\hline Without ICFJi (\%) & $48(94.1 \%)$ & $21(56.7 \%)$ & $15(6.5 \%)$ & $155(96.8 \%)$ & $239(50.1 \%)$ \\
\hline Total & 51 & 37 & 229 & 160 & 477 \\
\hline
\end{tabular}

CF, Internation al Classification of Functioning, Disability and Health; IEP, Individu alized Education Program.

Table II. Use of the Directorate-General for Innovation and Curriculum Development guidance materials through the special education process.

\begin{tabular}{|c|c|c|c|c|c|}
\hline & Referral form & $\begin{array}{c}\text { Preparation of the } \\
\text { individual team } \\
\text { meeting }\end{array}$ & Assessment script & Checklist & $\begin{array}{c}\text { Individualized } \\
\text { Education } \\
\text { Program }\end{array}$ \\
\hline$D G I D C$ fi $(\%)$ & $20(39.2 \%)$ & $16(43.2 \%)$ & $94(39.6 \%)$ & $157(66.2 \%)$ & $95(59.4 \%)$ \\
\hline Without DGIDC Ji (\%) & $31(60.7 \%)$ & $21(56.7 \%)$ & $143(60.3 \%)$ & $80(33.8 \%)$ & $65(40.6 \%)$ \\
\hline Total & 51 & 37 & 237 & 237 & 160 \\
\hline
\end{tabular}

DGIDC, Directorate-General for Innovation and Curriculum Development.

It should be noted however, that when using DGIDC checklist, $40 \%$ involved modifications characterized by more detailed ICF codes (third and fourth levels).

\section{What information sources are used inthe assessment process and are they related to the ICF?}

Of the 237 student records reviewed in this study, only 89 recorded information about the persons involved in the assessment process. The information related to codes for Body Functions were primarily provided by psychologists $(74.2 \%$ of the cases) and physicians (48.3\% of the cases), whereas information related to codes for Activities and Participation and to Environmental Factors were provided by regular teachers ( $80.9 \%$ and $73.0 \%$ of the cases), by special education teachers $(70.8 \%$ and $57.3 \%$ of the cases) and by parents $(33.7 \%$ and $66.3 \%$ of the cases) respectively. Indeed, the sources of information about students' assessment varied according to the role of health and educational professionals. These results reinforce the notion that the assessment and eligibility model elicited the participation of different persons and provided an interdependent relation among professionals including the interdisciplinary team.

The information about the methods used in assessment was available for 99 cases and varied from informal (61.2\%), such as observation, to formal methods (37.8\%), namely standardized tests. The dominant use of informal methods (e.g. observation, interview, questionnaires and portions of individual work) indicates a preferential focus of assessment on behavioral and performance indicators.

\section{What is the distribution of ICF components, chapters and codes used in the referral and assessment process?}

Of the key interest for analysis was the role of the ICF as a conceptual framework for the assessment and intervention processes within special education policy. In this context, 48 of the cases had information concerning the nature of reasons for the student's referral.

The deductive content analysis revealed 105 reasons for referral with $47.6 \%(n=50)$ related to Activities and Participation and $41.9 \%(\mathrm{n}=44)$ to Body Functions.
Diagnose represented $5.7 \%(\mathrm{n}=6)$ and the Environmental Factors $4.8 \%(n=5)$ of reasons for referral. These results indicate that the referral reasons were framed by functioning considerations, rather than by medical or psychological diagnosis. Documents for 214 included functioning profiles based on the ICF taxonomy. In keeping with the requirement in the law, there was a widespread use of the ICF taxonomy by the educational teams. However, one thing is complying the law requirements, other quite different is understanding what kind of functioning profiles the educational teams are describing. The answer to this question could demonstrate if the use of the ICF is promoting a holistic view of students.

The mean number of ICF codes referenced in functioning profiles was 24.3, with 12.8 of these relating to Activities and Participation, 6.8 relating to Body Functions and 4.7 relating to Environmental Factors. Multiple range testing using Bonferroni test with a set at 0.05 confirmed that the frequency of codes was significantly higher for the Activities and Participation component, compared to that of Body Functions $(p=0.001)$ and Environmental Factors $(\mathrm{p}=0.001)$. These results indicate that educational teams conducted assessments consistent with a biopsychosocial perspective of student functioning.

A detailed analysis of the nature of information within functioning profiles revealed that the most frequent sources were the chapters for mental functions, learning and applying knowledge and support and relationships within respective ICF components (Table III).

\section{What are the characteristics of student functioning and environmental factors defining eligibility decisions?}

This question was addressed by comparing the nature of functioning profiles of 156 students eligible for special education and 58 noneligible students. The comparison between the two groups did not reflect any significant differences in the mean number of codes for Body Functions $(\mathrm{t}(212)=1.02$, $\mathrm{p}=0.31)$ or Activities and Participation $(\mathrm{t}(212)=0.66, \mathrm{p}=$ 0.51) (Table IV). A significant group difference was found for the component of Environmental Factors, with more codes in the functioning profiles of eligible students than in those of noneligible students $(\mathrm{t}(212)=2.9, \mathrm{p}=0.003)$. 
Table III. International Classification of Functioning, Disability and Health codes distribution for various functioning domains.

\begin{tabular}{|c|c|c|}
\hline Components & Domains & $\%$ intra \\
\hline \multirow[t]{5}{*}{ Body functions } & Mental F. - b 1 & 73 \\
\hline & Neuromusculoske. F. - b7 & 9 \\
\hline & Voice and speech F. - b3 & 6 \\
\hline & Sensory F. and pain - b2 & 6 \\
\hline & Others - b4; bS; b6; b8 & 6 \\
\hline \multirow[t]{5}{*}{ Activities and participation } & Learning and applying knowledge - dl & 46 \\
\hline & Communication - d3 & $1 S$ \\
\hline & General tasks and demands - d2 & 10 \\
\hline & Interpersonal interactions and relationships - d7 & 7 \\
\hline & Others - d4; d6; d8; d9 & 22 \\
\hline \multirow[t]{5}{*}{ Environmental factors } & Support and relationships - e3 & so \\
\hline & Attitudes - e4 & $2 \mathrm{~S}$ \\
\hline & Products and technology -el & $1 \mathrm{~S}$ \\
\hline & Services, systems and policies -eS & 9 \\
\hline & Others - e2 & \\
\hline
\end{tabular}

Table IV. Mean number of codes referenced in functioning profiles of eligible and noneligible students.

\begin{tabular}{lccc}
\hline Components & $\begin{array}{c}\text { Eligible } \\
(\mathrm{n}=1 \mathrm{~S} 6)\end{array}$ & $\begin{array}{c}\text { Noneligible } \\
(\mathrm{n}=\mathrm{S} 8)\end{array}$ & Mean \\
\cline { 1 - 2 } & difference Body functions & 7.1 \\
Activities \& participation & 6.0 & 1.1 & \\
Environmental factors & 13.1 & 11.9 & 1.2 \\
Total of categories & $\mathrm{S} .0$ & 3.7 & $1.3^{*}$ \\
\hline
\end{tabular}

${ }^{*} \mathrm{p}<0.05$.

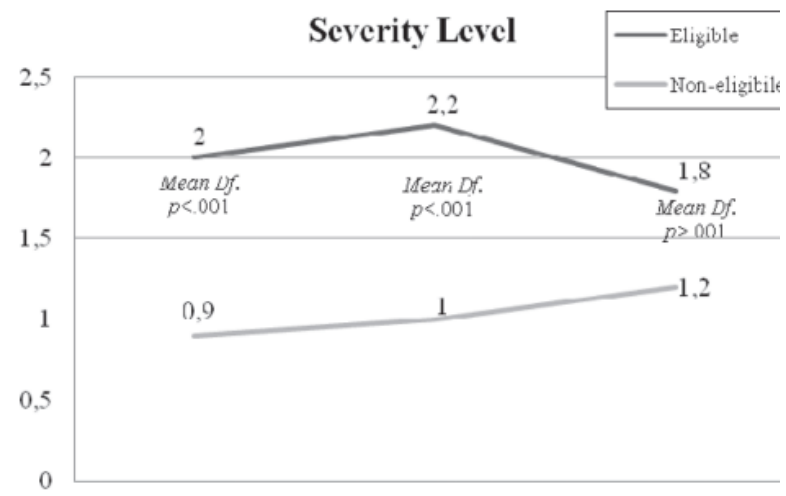

Figure 2. Severity mean of codes and mean difference in each International Classification of Functioning, Disability and Health component for eligible and noneligible students.

Although there were no significant differences in the total number of the ICF codes referenced of eligible and noneligible students $(t(212)=1.167, p=0.247)$, significant group differences were found for the severity level assigned to functioning categories. As shown in Figure 2, the severity level of functioning profiles of eligible students was higher than that of noneligible students, for limitations and restrictions in the Activities and Participation component and for impairments in Body Functions component.

Paired samples t-test confirmed higher severity levels for Body Functions impairments $(\mathrm{t}(185)=5.7, \mathrm{p}<0.001)$ and
Activities and Participation limitations/ restrictions $(\mathrm{t}(206)=$ $8.2, \mathrm{p}<0.001)$ of eligible students.

References to Environmental Factors were mainly centered on descriptions of facilitators and resources with $85.9 \%$ of codes found in profiles of both eligible and noneligible stu-

dents. The absence of barriers suggests an uncritical approach to the role of the environment, describing the surrounding supports without questioning their quality or adequacy to students' needs. The limitations and restrictions of Activities and Participation codes appeared to be related to individual impairments, without referencing the role of the environment in hindering students functioning.

\section{Conclusions}

The preamble of Portugal's new special education law (DecreeLaw n.3/2008) declared inclusive education principles as the basis for meeting the international challenge of creating a school for all. A focus of the law was to replace the reliance on diagnoses for identifying students for provision of special education services [9] with the ICF framework as the basis for describing students' profile of functioning.

The challenges introduced by the new special education law and, specifically, the application of the ICF, prompted the Ministry of Education to invite an external team to design a project to evaluate the national implementation of DecreeLaw (the authors of this paper).

The national results showed support for the use of the ICF in promoting a holistic view of students' functioning, incorporating dimensions of Body Functions, Activities and Participation and Environmental Factors in the assessment process.

Moreover, educational professionals captured the students' functioning emphasizing the Activities and Participation component in their profiles. The Body Structures component had a limited representation in functioning profiles, suggesting that it is not supporting the decision making by professionals regarding student eligibility for special education services. The Environmental Factors component was also not broadly implemented, with functioning 
profiles of students suggesting a linear relationship between participation and impairment without identifying the role of the environment. The development of assessment tools that considers environmental influences on students' functioning - namely measuring students' performance with and without environmental supports - is an important priority for improve the use of the ICF in educational contexts. Simeonsson et al. [14], have emphasized that promotion of an optimal environment for participation with a clear distinction between disability and impairment are needed for the development of good practice interventions with students with special education needs. In the assessment process, the contribution of professionals differs with psychologists and physicians providing information central to Body Functions, whereas regular and special education teachers and parents serve as key resources for information about Activities and Participation and Environmental Factors. The implementation of a multidimensional approach defined by the ICF framework calls for the involvement of different persons and knowledge domains in creating interdependent contributions by professionals $[15,16]$.

The comparison of functioning profiles of eligible and noneligible students showed that the difference between groups was not the number of categories in the profiles, but rather the severity assigned to them. In fact, the significant differences pertained to the severity of limitations/restrictions experienced in Activities and Participation and the permanent nature of impairments in Body Functions. The results of this evaluation study provide support for the intent of the new Decree-Law to incorporate a functional basis for determining eligibility in the provision of special education services to students with disabilities. Specifically, findings demonstrate that the use of the ICF use can support assessment and eligibility processes based on functioning information, rather than on medical or psychological diagnoses. Working within the ICF component framework of human functioning, documentation of the nature and severity of functioning can serve as the basis for differentiating eligible and noneligible students for special education services. Adding to this important contribution, functional profiles based on the ICF can yield a gradation of students' functioning in support of decision making for the most appropriate educational intervention for the student.
Declaration of Interest: The authors report no declarations of interest.

\section{References}

1. Ebersold S, Evans P. A Supply-side approach for a resource-based classification system. In: Florian L, McLaughlin MJ, editors. Disability classification in education: issues and perspectives. Thousand Oaks, CA: Corwin Press; 2008. pp 31-46.

2. World Health Organization. ICD-10: International Statistical Classification of Diseases and Related Health problems. Geneva: WHO; 1992.

3. Florian L, McLaughlin MJ. Disability classification in education: issues and perspectives. Thousand Oaks, CA: Corwin Press; 2008.

4. Sanches-Ferreira M. Educaao Regular, Educa ao Especial - uma hist6ria de separaao. Porto: Edioes Afrontamento; 2007.

5. World Health Organization. International Classification of Functioning, Disability and Health. Geneva: World Health Organization; 2001.

6. World Health Organization. International Classification of Functioning, Disability and Health - version for children and youth. Geneva: World Health Organization; 2007.

7. Simeonsson R. Defining and classifying disability in children. In: Field MJ, Jette AM, Martin L, editors. Disability in America: A new look. Washington, DC: The National Academies Press; 2006. pp 66-87.

8. Ustiin BT, Chatterji S, Bickenbach ), Kostanjsek N, Schneider M. The International Classification of Functioning, Disability and Health: a new tool for understanding disability and health. Disabil Rehabil 2003;25:565-571.

9. Ministerio da Educaao. Decreto-Lei n. ${ }^{0}$ /2008. Diario da Republica, 7 de Janeiro. 2008.

10. European Agency for Development in Special Needs Education. Identification of special educational needs - Portugal. 2009. Retrieved from: http://www.european-agency.org/ country- information /portugal/ national-overview lidentification -of-special-educational- needs

11. Sanches-Ferreira M, Simeonsson R, Maia M, Pinheiro S, Tavares A, Alves S. Projecto da Avaliaao Externa da Implementaao do Decreto-Lei n. ${ }^{0}$ 3/ 2008. Lisboa: Direcao-Geral de Inovaao e de Desenvolvimento Curricular. 2010. Retrieved from: http://www.dgidc.min-edu.pt/ educacaoespecial/ data/ensinoespecial/ estudo_simeonsson.pdf

12. Capucha L, Pereira F, Crespo A, Correia C, Cavaca F, Croca F, Breia G, Micaelo M. Educaao especial - manual de apoio a pr:itica. Lisboa: direcao-geral de inovaao e de desenvolvimento curricular. 2008.

13. Cieza A, Geyh S, Chatterji S, Kostanjsek N, Ostiin B, Stucki G. ICF linking rules: an update based on lessons learned. J Rehabil Med 2005;37:212-218.

14. Simeonsson R, Leonardi M, Bjorck-Akensson E, Hollenweger ), Lollar D et al. ICF-CY: a universal tool for practice policy and research, Meting of WHO collaborating centres for the family of international classifications. Tunisia. 2006.

15. DePolo G, Prada! M, Bortolot S, Buffoni M, Martinuzzi A. Children with disability at school: the application ofICF-CY in the Veneto region. Disabil Rehabil 2009;31:67-73.

16. Tokunaga A. The attempt of the practical application of International Classification of Functioning, Disability, and Health (ICF) as a tool for collaboration among various professionals: a perspective on its applicability to "individualized educational support plan". NISE Bulletin 2008;9: 1-26. 